\title{
LA IDEA DE AMPARO \\ Y EL PRINCIPIO \\ DE SUBSIDIARIEDAD
}

Por Ricardo MEDINA RUBIO

Profesor Adjunto de Derecho Político

SUMARIO:

I. La tradición aragonesa.

II. La idea de amparo.

III. El amparo y la Constitución de 1.978.

IV. El recurso de amparo constitucional (RAC) y el principio de subsidiariedad.

V. Conclusión.

Publicado en "Trib. Const." vol. II. Dir. G. de lo Contencioso del Estado. Madrid. Jornadas de Estudio (Mayo 1.980). 


\section{LA TRADICION ARAGONESA}

La Ley Orgánica del Tribunal Constitucional (LOTC) de 5 de Octubre de 1.979, es uno de los elementos que más eficazmente pueden contribuir a la recuperación para el constitucionalismo espananol del lugar que ocupaba antes del régimen autoritario del general Franco. Supone el reencuentro con una tradición(1), entrevista en períodos más o menos largos y sofocada por los avatares políticos, que se remonta a tiempos incluso anteriores a lo que se considera el comienzo del constitucionalismo inglés, en el siglo XIII; y tan versátil que su influencia se deja notar en los diversos sistemas de protección jurisdiccional de los derechos y libertades.

Dicha tradición no es el resultado de planteamientos teóricos y abstractos, a pesar de la indudable trascendencia de la secularización del Derecho Natural, debida a la Escolástica española del Siglo de Oro, sino más bien de una práctica y un sentir jurisprudenciales, una de cuyas fuentes hay que buscarla en épocas muy tempranas del Derecho histórico aragonés.

Los privilegios y fueros que gozaba la nobleza medieval pueden ser considerados como los precedentes directos de las modernas libertades y derechos humanos no, ciertamente, por el contenido de los mismos que, en realidad se reducian a hacer efectivas las relaciones de vasallaje, con frecuencia harto crueles e inhumanas, sino por su aspecto formal y funcional ya que, en el equilibrio de los poderes propio de la Edad Media - Cortes/Rey-, las actitudes y compartamientos generados por las relaciones sociales de la época eran sancionados por el monarca que se comprometía a respetarlos y la costumbre contribuía a consagrarlos a través del tiempo. Ya entonces se observa que no bastabà el compromiso formal y de ahí la necesidad de crear unos medios que garantizaran el cumplimiento de lo formulado. También de entonces es la idea de confiar esta misión a un "tercer poder", una especie de poder arbitral al que quedarían sometidos los otros dos; desde el primer momento esta misión pareció estar dedicada a la Justicia que, en sus diferentes formas, según los paises, consigue arbitrar procedimientos de garantías para los privilegios feudales. Así, las Cortes aragonesas reunían entre sus funciones la de resolver los recursos por agravios. Asi, también, el Tribunal de Westminster o el Justiciazgo de Aragón; a pesar de que en el origen, estos órganos no tienen autonomía y no son sino los sustitutos de la Corona en una función privativa de ésta: la Justicia. Pero los reyes de entonces, más preocupados por la guerra y por otros asuntos políticos, van delegando progresivamente en esos órganos aula regis dicha función que va adquiriendo poco a poco su autonomía.

Precisamente en Aragón, su particular régimen político en el que la soberanía parece, desde el principio, como si estuviera compartida entre el 
poder real y la nobleza, se hace propıcio el desarrollo de las instituciones de garantía y también, quizá como consecuencia de ello, la necesidad de un tercer poder, de naturaleza arbitral, que es el Justicia, al que quedan sometidos, como si de un Tribunal Constitucional contemporáneo se tratata, el Rey y las Cortes.

El sistema histórico aragonés de protección jurisdiccional, integrado por los procesos de Firma, Aprehensión, Inventario y Manifestación, resulta no sólo un sistema complejo, muy utilizado en la práctica, sino también, en ocasiones, más completo que los sistemas actuales(2); ello es debido al elevado sentido jurídico del Reino de Aragón en donde se dan ideas y procedimientos jurídicos de plena vigencia actual o, al menos, de cierta repercusión como esa especiè de soberanía compartida dada en la relación Corte/Rey/Justicia que recuerda a la moderna división de poderes. Aunque las tres instituciones no coincidan plenamente con las funciones actuales (legislativa, ejecutiva y judicial) su finalidad viene a ser la misma: limitar el poder, buscar el equilibrio y el control mutuo. De ahí la importancia del Justicia en su función de árbitro y garante de los privilegios feudales(3).

La tradición parece verse continuada modernamente por diversas instituciones del Derecho de Indias (recurso de fuerza, juicio de residencia, amparo colonial) cuya influencia en el juicio de amparo mexicano es ampliamente reconocida(4). A su vez, el desarrollo de la idea de amparo en Latinoamérica sirvió curiosamente durante la II República para reencontrar la tradición de la que se había visto nutrida, en un conjunto de instituciones (Tribunal de Garantías Constitucionales. Tribunales de urgencia y juicio de amparo) que ya incluyen elementos de los sistemas continentales de protección jurisdiccional.

En este sentido, el sistema español de protección jurisdiccional, establecido por la Constitución de 1.978, puede considerarse como la culminación del intento omnicomprensivo, ya manifestado en la II República, de aunar la tradición española, cercana en su espíritu a la anglosajona, con los logros contemporáneos de la llamada Justicia constitucional de la Libertad (JCL)(5). A esta unión entre la tradición revivida y la racionalización contemporánea de los procedimientos de protección jurisdiccional muy bien puede denominarse "amparo" o "derecho de amparo" no sólo por emplear un término tributario de la primera manifestación moderna, de origen en parte hispánico, de dichos procedimientos-amparo mexicanosino también porque tal término expresa perfectamente la significación de lo que todo sistema de protección jurisdiccional quiere realizar respecto de los derechos y libertades. De esta manera, la idea de amparo se acerca al criterio básico que La Pérgola define con las siguientes palabras: “L'organo delle garanzie costituzionali dovrebbe essere, insomma, fin dove possibile, il giudice dell'annuallamento (come il giudice costituzionale continentale) e al tempo stesso il giudice del diritto soggettivo (come il giudice anglosassone)m(6). 


\section{LA IDEA DE AMPARO}

El amparo no ha de entenderse como referido a una institución concreta-Recurso de Amparo Constitucional (RAC) - sino como ef conjunto de instituciones y funciones que en la tradición española y latinoamericana consiste en la actuación jurisdiccional tendente a evitar o a interrumpir el acto supuestamente lesivo de un derecho fundamental. La indemnización, el resarcimiento, la nulidad del acto de los poderes públicos, aunque sean muchas veces los únicos resultados de la protección jurisdiccional, no constituyen de suyo la finalidad específica del amparo sino más vien valores añadidos a su verdadero sentido. "Lo importante en cuanto a la tutela de los derechos fundamentales, sea tutela ordinaria o tutela constitucional, es que la ejecución del acto no prive del disfrute del derecho. Por tal razón las leyes deben establecer, claramente, los modos de suspender la ejecución del acto lesivo, tanto en una vía como en otra, o los medios de paralizar la continuación de los actos ejecuitivosw(7). De lo que se trata, pues, es de dar una protección "especial» por la cualidad de los derechos que se protegen de ser inherentes a la persona(8), lo que determina que de no existir efectivamente dichos derechos en su ejercicio, la existencia de aquélla está también en peligro. De esta manera la finalidad del amparo consistiria en impedir, en lo posible, la ejecución del acto lesivo; de ahí que se considere que no procede el amparo icontra actos cuyos efectos hayan cesado con anterioridad a la petición de amparow(9) que irá encaminada a evitar la consumación del acto o al menos su interrupción. Parece esencial, por tanto que los procedimientos de protección jurisdiccional de los derechos y las libertades garantizados constitucionalmente deban reunir como características:

La inmediatez en la admisión de la demanda por la autoridad jurisdiccional correspondiente.

La sumariedad en el procedimiento.

La preferencia respecto de otros asuntos que no traten de los derechos garantizados por la Constitución.

Notas, estas dos últimas, que se hallan establecidas en el artículo 53 de la constitución y que deberán realizarse en procedimientos directivos y expeditivos cuya ejecución represente el principal obstáculo al acto lesivo y cuya puesta en marcha no suponga ningún problema o dificultad al sujeto agraviado. Por otra parte, los requisitos de sumariedad y preferencia, según ALMAGRO NOSETE, no son más que matizaciones del derecho fundamental a la justicialidad establecido en el artículo 24 de la constitución, es decir, el derecho de toda persona a acudir a los jueces para la tutela de sus derechos e intereses; lo que no hace sino reforzar la sustancia de ambos requisitos tenidos en cuenta ya por TOCQUEVILLE cuando afirmaba en "La Democracia en América" que "con pequeños procesos puestos al al- 
cance de todos los ciudadanos, se lograba garantizar la libertad mejor que con grandes procedimientos judiciales a los que nunca se recurre o se emplean demasiado tarde»(10). así mismo, FIX-ZAMUDIO señala que "el problema de la impartición de una justicia pronta, expedita y adecuada constituye una de las exigencias fundamentales de todo régimen democrático, pero al mismo tiempo una aspiración que ha resultado muy difícil de alcanzarn(11).

La necesidad de tales procedimientos sencillos, directos y expeditivos viene aumentada por el hecho de que los actos de los poderes públicos casi siempre se presentan con la presunción de la legalidad «que dificulta su enjuiciamiento ordinario si no se establecen medios específicos de tutelaw,(12), y útilizando medios coercitivos y disponibilidades que aseguran el acto y lo hacen más eficiente en su realización, factores ambos que propician una indefensión mayor del agravio y evidencian la desproporción existente entre el poder del Estado y el del indivíduo, desproporción peligrosa para el segundo por cuanto el poder del Estado se manifiesta normalmente en actos de las personas físicas que lo representan o que figuran como agentes del mismo, con todos.los errores e imperfecciones que las conductas personales pueden llevar consigo, pero también, con las consecuencias y la contundencia que un acto estatal supone. Por ello, es de agradecer a la L. O. T. C. la especificación y descripción de los actos susceptibles de ser impugnados: "Disposiciones, actos jurídicos o simple vía de hecho de los poderes públicos del Estado, las Comunidades Autónomas y demás entes públicos de carácter territorial, corporativo o institucional, así como de sus funcionarios o agentes" (artículo 41, L. O. T. C.). De esta manera, parece continuarse el criterio establecido ya en la II República en la que, según ALMAGRO NOSETE, el recurso de amparo se refería a "acto concreto de autoridades»(13).

\section{EL AMPARO ESPAÑOL}

En España, la idea de amparo se caracteriza actualmente por concretarse en un sistema de protección jurisdiccional, establecido por la Constitución de 1.978 y desarrollado-incompletamente-por la reciente L. O. T. C. y por otras normas(14), con dos finalidades: el control de la constitucionalidad de los actos sin valor de ley de los poderes públicos(15), y la salvaguarda del ejercicio efectivo de los derechos garantizados por la Constitución frente a los mismos actos. El amparo considerado como conjunto de instituciones encargadas de proporcionar una protección jurisdiccional de los derechos y libertades, no puede agotarse naturalmente en la R. A. C. sino que habrá que buscarlo también en otros lugares de la Constitución como son el artículo 17, que establece el procedimiento de habeas corpus y el artículo 53-2 que recoge lo que podria denominarse "amparo ordinarion. 
Al extenderse el amparo español de esta manera desde la jurisdicción ordinaria (poder judicial) a la constitucional (Tribunal Constitucional) no puede identificarse plenamente ni con el amparo mexicano, que no implica una jurisdicción constitucional en sentido estricto, ni con la J. C. L. que sólo se refiere a los poderes y actuaciones del juez constitucional; si bien, tanto en México como en España es evidente la coincidencia en considerar el amparo como un conjunto de instituciones cuyo objetivo primordial consiste en la evitación o interrupción del agravio(16).

El amparo español, con las características esbozadas más arriba, es decir, sistema de protección jurisdiccional tendente a evitar o interrumpir el acto lesivo de un derecho garantizado por la Constitución (artículo 1430) mediante procedimientos especiales (sumariedad y preferencia), que se concreta en las tres instituciones citadas, parece realizarse, sobre todo, en el habeas corpus del artículo 17 de la Constitución cuyos antecedente directos pueden ser reencontrados indistintamente por dos vías, la del amparo mexicano, de tanta influencia en la Constitución de la II República española, que proporciona elementos de habeas corpus anglosajón, y la del Derecho histórico aragonés, y particularmente el derecho de manifestación de personas, muy similar al anterior.

Según MILTON GREENBERG(17), el habeas corpus es considerado en Norteamérica como una orden judicial a court order que obliga al funcionario official que tiene la custodia de una persona a llevarla ante el Tribunal y mostrar la causa de su detención. Esta institución está tan arraigada en el sistema judicial estadounidense que aunque el Presidente LINCOLN suspendio el writ of habeas corpus por propia iniciativa, dentro de los poderes exhorbitantes que caracterizan la Presidencia de los Estados Unidos, el Congreso anuló tal suspensión. Así mismo, varias constituciones estatales prohiben absolutamente toda suspensión del habeas. corpus que sólo puede ser llevada a cabo por el Congreso en caso de rebelión o invasión. Todo esto da idea de que el habeas corpus es considerado generalmente como la más importante garantía de la libertad individual que previene las detenciones y encarcelamientos arbitrarios cuyo paradigma se expresa en. la ya clásica imagen de la "terrorífica llamada nocturna a la puerta" y la consiguiente desaparición de la persona. De esta manera, el habeas corpus parece.ser el procedimiento que mejor responde al sentido esencial del amparo de evitar o interrumpir la violación del derecho, porque consiste en traer el cuerpo del detenido a la presencia del juez (manifestar, en el Derecho histórico aragonés), cuando éste, de oficio o a instancia de parte, así lo requiere porque sospecha que en la detención se ha podido violar un derecho garantizado por la Constitución, es decir, cuando aún no ha cesado el acto lesivo y puede quedar interrumpido.

En la actualidad del Derecho español, el habeas corpus no está todavía desarrollado por la preceptiva Ley Orgánica lo que significa que 
continúa la indefensión frente a las detenciones arbitrarias de los poderes pụ́blicos de una de las libertades fundamentales, así consideradas por la doctrina francesa porque sin ellas no es posible el ejercicio de las otras(18). Esta laguna legal, de tan negativas consecuencias para el sentido del amparo, sólo puede verse soslayada-indefinidamente-por el principio establecido en el artículo 9 de la Constitución, que exige a los poderes públi$\cos y$, por tanto, a los jueces la promoción de las condiciones necesarias para que la libertad sea real y efectiva. Por otra parte, tampoco parece adecuada la fórmula del artículo 17 de la Constitución, que establece el procemiento de habeas corpus en favor de la persona "detenida ilegalmente", lo que parece indicar que en toda detención ilegal habrá que demostrar, en primer lugar, la ilegalidad del acto de los poderes públicos, lo cual obstaculizaría el procedimiento y desnaturalizaría enormemente el sentido del amparo contenido en la institución.

Por la cualidad del derecho que se protege con el habeas corpus no sólo basta la sumariedad y preferencia de los trámites sino también el que la mera sospecha de la violación ponga en marcha el procedimiento. En ocasiones, el mandamiento de habeas corpus dará como resultado que el juez confirme la detención o el encarcelamiento del supuesto agraviado. No es, pues, un recurso dedicado a verificar que una detención se ha llevado a cabo ilegalmente sino a evitar que, en todo caso, ésta se produzca.

El resto de los derechos garantizados por la Constitución se halla protegidó por el llamado "amparo ordinario» del artículo 53-2 de la Constitución, que establece un procedimiento de carácter sumario y preferente que se actúa ante el juez ordinario. Desde el punto de vista teórico, el amparo ordinario puede ser considerado una institución "puente" por su carácter de procedimiento previo al RAC y porque se trata de una institución híbrida, a caballo entre ambas jurisdicciones, la ordinaria y la constitucional; parece cumplir así aquel criterio de LA PERGOLA, expresado más arriba de reunir en una sola institución elementos de los sistemas continentales de protección jurisdiccional (J. C. L.) y de los sistemas anglosajones(19).

Por el momento, con el amparo ordinario ocurre lo mismo que con el habeas corpus: todavía no ha sido adecuadamente desarrollado, como se desprende de la Disposición transitoria 2 a $^{a}-2$, L. O T. C., que «provisionalmenten reconoce a la Ley de protección jurisdiccional de los derechos fundamentales (L. P. J.), de 26 de Diciembre de 1.978, como ley de desarrollo del amparo ordinario. Dicha ley no sólo puede ser un caso claro de inconstitucionalidad por ser una ley ordinaria que desarrolla una materia-la protección jurisdiccional de los derechos garantizados constitucionalmente-que la Constitución exige lo que sea por ley orgánica(20) sino también, porque la dificultad y duración de los trámites no parece respetar la finalidad del amparo, como ya se verá más adelante en este trabajo. 
El tercer instituto que configura el amparo español es el R. A. C. establecido en el Titulo III de la L. O. T. C., que viene a cumplir respecto de los actos de los poderes públicos el mismo papel que la citada ley atribuye a la declaración de inconstitucionalidad (Título II) respecto de las disposiciones normativas y actos con fuerza de ley.

El antecedente más directo del R. A. C. hay que buscarlo en el recurso constitucional propio de sistemas de jurisdicción constitucional como el alemán, el suizo y el austríaco, y más concretamente en el llamado récurso directo por la regulación de su procemiento de admisión. Pero es, sobre todo el Verfassungbeschwerde alemán, creado por una ley ordinaria de 1.951 y elevado a la categoría constituciónal en 1.969, la institución más semejante al R. A. C. en el Derecho comparado, lo que le hace distanciarse del amparo mexicano que, como ya se ha indicado, no presupone una jurisdicción constitucional. Muy cercano está, por el contrario, del recurso de amparo de garantías individuales, establecido por el artículo 121 de la Constitución de la II República del que recibe el nombre y parece reproducir su misma génesis, la Constitución austríaca de 1.920, de inspiración kelseniana y, en cierta medida, el juicio de amparo mexicano, a lo que hay que añadir, para el R. C. A., los logros de la J. C. L. de la postguerra.

La denominación de "recurso", según ALMAGRO NOSETE621) no parece ser la más adecuada puesto que, al configurarse el Tribunal Constitucional como una jurisdicción independiente, y a pesar de ser preceptivo el agotamiento de otras vías previas, el R. A. C. no supone la culminación de una vía jurisdiccional única, sino un proceso que se inicia y se acaba en una sola instancia; estaría justificada, no obstante, la denominación de recurso por el hecho de ser los mismos bienes jurídicos protegidos los que se dan en ambas vías, ordinaria y constitucional.

La finalidad de la R. A. C. viene a ser la misma que se ha señalado para el amparo en general, y viene expresada en el artículo $41-3$, L. O. T. C.: "restablecer o preservar los derechos o libertades"; sin embargo, cabe cuestionarse si esta finalidad puede ser cumplida en un proceso que exige el agotamiento de la vía judicial previa, la misma denominación de recurso, como ya se ha visto, inapropiada, hace pensar en un acto lesivo ya consumado y, por tanto, irreversible que determina la imposibilidad de su interrupción y el consecuente restablecimiento del derecho violado.

La L. O. T. C. establece cuatro tipos de actos susceptibles de ser impugnados por el R. A. C.:

Asambleas legislativas de las Comunidades autónomas y de sus organos.

-Actos del gobierno central y de los gobiernos autónomos.

-Actos del poder judicial. 
-Actos de la autoridad militar que violen el derecho a la objeción de conciencia.

En el primer caso, actos de los órganos legislativos centrales y àutónomos, el R. A. C. funciona como un medio de protección estrictamente directo, no se exige recurso previo y el acto supuestamente lesivo pude ser impugnado directamente ante el Tribunal Constitucional, pasados tres meses desde su ejecución.

En el segundo caso, actos de los gobiernos central y autónomos, es quizá donde el R. A. C. presenta sus características propias. Aquí el agraviado podrá dirigirse al Tribunal Constitucional, mediante el R. A. C., una vez producido el fallo del juez ordinario en un proceso que habrá debido ser preferente y sumario; el plazo para la interposición del R. A. C. se acorta, veinte días, con respecto al supuesto anterior y por ello la idea de amparo queda reforzada.

Por otra parte, el artículo 43, L. O. T. C. es quizá el único caso en que habla de amparo sin referirse exclusivamente al R. A. C. sino a ambos procedimientos, el R. A. C. y el amparo ordinario del artículo 53 de la Constitución. Según el mencionado artículo de la $L$. O. T. C.: "el recurso sólo podrá fundarse en la infracción por una resolución firme de los preceptos constitucionales que reconocen los derechos y libertades susceptibles de amparon. Aunque no pueda concluirse con plena seguridad que la intención del legislador al redactar este precepto era la de plasmar la idea omnicomprensiva del amparo, ésta queda reflejada de alguna manera y, al menos, da pie para considerar teóricamente un sistema de protección en el que quedan incluidas ambas instituciones al considerarlas protectoras de los mismos derechos y libertades.

La distinción que la ley hace respecto de los actos susceptibles de ser impugnados "actos jurídicos o simple vía de hechon, es de la máxima importancia pues en el primer caso el acto viene avalado por su carácter de acto administrativo, que puede estar viciado pero que lo distingue claramente de los actos meramente fácticos que o han desbordado los límites de la disposición administrativa que les ha dado origen o carecen en absoluto de todo fundamento jurídico lo que agrava su condición de acto ilegítimo.

En el tercer caso, actos u omisiones del poder judicial que vulneran de forma directa e inmediata algún derecho garantizado, el R. A. C. queda convertido en un simple ricorso di annullamento, por emplear la expresión de LA PERGOLA(22), que tiene también semejanza con el llamado "amparo judicial„(23), y cuyo procedimiento obliga a agotar previamente la vía judjcial ordianria.

El que, a diferencia de los dos casos anteriores, impugnaciones por actos de los poderes, legislativo y ejecutivo, la impugnación de los actos 
del poder judicial inclùya expresamente (artículo 44-b) L. O. T. C.) las omisiones parece querer equilibrar de alguna manera el trato más favorable que recibe la institución judicial por parte de la jurisdicción constitucional. Trato favorable que se reafirma en el artículo 54, L. O. C. T., ("Cuando la Sala conozca del recurso de amparo respecto de decisiones de los Jueces y Tribunales limitará su función...") y que debe estar en relación con el carácter de mayor independencia que le es propio a la citada institución y con el papel que cumple de "amparador" natural del individuo. El poder judicial, desde antiguo, ha tenido su instalación propia entre el Estado y la Sociedad, con un sentido de independencia que ha determinado su cualidad de árbitro, lo cual, por otra parte, parece realizarse mejor en los sistemas judiciales de influencia anglosajona y particularmente en el norteamericano cuyos jueces son tan independientes del resto de los poderes que, a pesar de la rigidez característica en la separación de poderes, pueden llevar a cabo el control sobre los actos del legislativo (control de la constitucionalidad de las leyes federales y de las de los estados) no estando permitido lo contrario(24).

Por otra párte, la consideración especial hacia el poder judicial vueve a reafirmarse en el artículo 46-1-b) L. O. T. C. cuando se limita la legitimación para interponer el R. A. C., además de al Ministerio Fiscal y al Defensor del Pueblo "a la persona directamente afectada", o sea, a quien ha sido parte en el proceso, quedando excluídos, por tanto, los terceros intervinientes o no en dicho proceso. ALMAGRO NOSETE critica esta "limitación" consagrada por la Jurisprudencia anterior a la Constitución, recomendando que "debe a toda costa evitarse una interpretación excesivamente formalista de los preceptos reguladores que prácticamente convierten al amparo, justo en lo que no es; una carrera de obstáculos para conseguir, al cabo de un tiempo perdido, una sentencia del Tribunal Constitucional que pueda ser un flamante "papel mojadon. Los terceros al proceso tienen que ser sujetos también legitimados para acudir al recurso de amparo si una resolución judicial ler perjudica en sus derechos fundamentalesw(25).

Por último, el cuarto tipo de actos susceptibles de ser impugnados mediante R. A. C. son aquéllos que suponen una violación del derechi a la objeción de conciencia y que, al igual que en el caso de la impugnación de los actos del poder legislativo, pueden ser recurridos directamente una vez producida la resolución de las autoridades militares lesiva del citado derecho.

El hecho de que tales actos constituyan un tipo específico dentro del R. A. C. $\dot{y}$, por tanto, el interés del legislador de dar una protección especial-a pesar de que el derecho a la objeción de conciencia pertenezca en pura lógica a la esfera de la libertad religiosa, ideológica y de culto, reconocida en el artícúlo 16 de la Constitución, y de que, también en pura 
lógica, la autoridad causante del agravio pertenece a la organización del poder ejecutivo-hace pensar que el constitucionalismo español se hace eco de la preocupación que pór los ejércitos permanentes se ha mantenido, más o menos vivamente, desde los presupuestos liberales; si bien, como se deduce de la práctica de los acontecimientos históricos, el liberalismo y el constitucionalismo han variado notablemente sus posturas respecto a la consideración del "poder militar", como puede verse en la comparación del punto 13 de la Declaración de derechos de Virginia del 12 de Junio de 1.776 que aconseja "deberían evitarse en tiempos de paz, como peligrosos para la libertad, los ejércitos permanentes", y del artículo 8-1 de la Constitución española de 1.978 que atribuye a las Fuerzas Armadas la defensa del Ordenamiento constitucional.

\section{EL R. A. C. Y EL PRINCIPIO DE SUBSIDIARIEDAD.}

Se ha señalado frecuentemente la necesidad de que la interposición del recurso constitucional se vea atemperada por determinado filtros(26) que eviten un número excesivo de recursos sobre asuntos de escasa importancia. Este criterio es aceptado por el propio Tribunal Connstitucional Federal con el argumento de que upor razones de seguridad jurídica sólo excepcionalmente pueden ser cuestionadas las decișiones formalmente válidas o firmes de otros tribunales o autoridades»(27). Esta misma necesidad, considerada como un logro de la seguridad juridica se ve reconocida también por los amparistas mexicanos que, no obstante, tratarse el amparo mexicano y el recurso constitucional de instituciones formalmente distintas, consideran favorable la oportunidad de establecer filtos a la iniciativa del amparo que eviten el supuesto caótico de que todas las situaciones subjetivas puedan ser susćeptibles de protegerse por procedimientos extraordinarios, lo que, además del despecho al principio de economía procesal, puede producir una desnaturalización del amparo al convertirse en una especie de "superrevisión", con lo que perdería su condición de procedimiento especial y extraordinario para la defensa de intereses jurídicos claramente cualificados.

En principio, hay que señalar que el establecimiento de filtros que impidan un funcionamiento irregular del recurso se ha convertido en una nota sustantiva de los sistemas de protección que implican una jurisdicción constitucional como última instancia en la protección de los derechos garantizados. Sin embargo, la regulación de estos filtros se presenta particularmente delicada porque de prevenir la eficacia del amparo pueden pasar a ser un obstáculo a su finalidad si dicha regulación no es lo suficientemente flexible.

Entre las diversas soluciones que existen para configurar dichos filtros destaca, por ejemplo, el examen del recurso en vía preventiva por 
una comisión de tres jueces "Dreier Ausschuss" para constatar la procedencia de aquél.

Otra posible solución, cercana a la anterior, es la estadounidense que se concreta en la "petition for a writ of certiorari" que siguiendo la caracterización que de ella hace CASCAJO, se trata de "Uno de los más conocidos remedios del Derecho anglosajón para'la tutela jurisdiccional del ciudadano, que se emplea para someter delante de una Corte Suprema la decisión de cualquier Tribunal inferior, a fin de que sea controlada su validez. Y así, por ejemplo, en el caso americano, a través de una petition for a writ of certiorari, en la que se exponen las razones por las que se estima que la cuestión puede ser examinada por la Corte, corresponde a la misma Corte, según su discrecional apreciación, emanar o no el llamado writ y, consecuentemente, pronunciarse o no sobre la controversiaw(28). Solución, por otra parte, recomendada por FIX-ZAMUDIO(29) para ser tenida en cuenta en el futuro funcionamiento del Tribunal Constitucional.

Aunque no se trate expresamente de un filtro de esta naturaleza establecido por la Constitución, la determinación expresa de cuáles son los derechos susceptibles de ser protegidos por el recurso constitucional, que es el caso español, puede contribuir a evitar que todas las situaciones subjetivas den lugar al amparo y éste se convierta, como se indicaba más arriba en una "superrevisión".

De entre todas estas posibles soluciones tributarias de la economia procesal, destaca el llamado principio de subsidiariedad que sin duda se presenta no sólo como el medio más eficaz de filtrar las demandas de amparo sino también, en ocasiones, como un elemento esencial del mismo.

Por el principio de subsidiariedad, se exige que en la reclamación se agoten las vias jurisdiccionales ordinarias antes de interponer el recurso constitucional. Este criterio está fuertemente asentado en la doctrina y jurisprudencia alemanas como se desprende del párrafo 90 , apartado 1 de la Ley del Tribunal Constitucional Federal al establecer que "cuando la lesión pueda ser reparada por la vía jurídica normal, el recurso de amparo no puede ser interpuesto sino después de haberse agotado dicha vía jurídican. Sin embargo, la rigidez que caracteriza una tal aplicación del principio se ve flexibilizada por dos excepciones de carácter muy amplio: «El Tribunal Constitucional Federal puede «decidir de inmediato sobre un recurso de amparo interpuesto antes del agotamiento de la vía jurídica, cuando ese recurso sea de interés generl o cuando, de no hacerlo así, se le irrogue al recurrente un perjuicio grave e inevitable". (parágrafo 90 , apartado 2, L. T. C. F.)"; además dicho Tribunal puede expedir un mandato provisional "einstweilige Anordnung" "cuando ello sea de imperiosa urgencia para evitar graves perjuicios, para prevenir una violencia inminente o por alguna otra razón de importancia para el bien común" (párrafo 43, apartado 1 , L. T. C. F.). 
Se ve, por tanto, que el principio de subsidiariedad, cuya estricta aplicación podría mermar la capacidad de amparo, puede ser soslayado no con mucha dificultad. Piénsese que de la naturaleza de los derechos protegidos pueden derivarse perjuicios "considerables e inevitables" si la reclamación no se desarrolla con la sumariedad propia de todo sistema de protección jurisdiccional. No parece muy difícil hacer valer dichas excepciones del sistema alemán, «la sala admite el recurso de amparo, "cuando por lo menos dos de sus miembros consideran que la decisión implicará el esclarecimiento de una cuestión jurídica de índole constitucional, o cuando la falta de esa decisión puede irrogar al recurrente un prejuicio grave e inevitablei (parágrafo 93-a), apartado 4, párrafo 2, L. T. C. F.)»(30).

En España, la Constitución establece esos filtros a través del principio de subsidiariedad y en la determinación taxativa de los derechos garantizados. Respecto a esto último, quedan fuera del amparo, para extranjeros, la igualdad ante la ley (artículo 14); la libertad de residencia y circulación por el territorio nacional (artículo 19); el derecho al sufragio activo y pasivo y a participar en los asuntos públicos (artículo 23); y el derecho de petición individual y colectiva (artículo 29). Y tampoco son susceptibles de amparo para los ciudadanos españoles los derechos reconocidos en la Sección 2. ${ }^{a}$, capitulo $2 .^{\circ}$, Título I. Hay que destacar, no obstante, que la inclusión dentro de los derechos garantizados jurisdiccionalmente del derecho a la educación y el de huelga, así como la exclusión del derecho de propiedad privada, garantizado en otros Ordenamientos, constituye un serio avance en la constitucionalización de los derechos llamados sociales, en el sentido de considerarlos fundamentales y procurarles la adecuada protección.

- Respecto al principio de subsidiariedad, reconocido en artículo 53-2 de la Constitución y regulado en la L. O. T. C., hay que señalar que ofrece características distintas del caso alemán. Aquí, la subsidiariedad no puede entenderse como un principio general con excepciones sino que se manifiesta de manera diferente, con mayor o menor intensidad, según sea la procedencia del acto lesivo. Por una parte, no parece que pueda hablar- 
se de subsidiariedad en la impugnación de los actos del poder legislativo y de la autoridad militar. En estos dos casos, como ya se ha indicado más arriba, el R. A. C. funciona como un recurso directo que se interpone inmediatamente de producida la resolución lesiva; si bien, son los plazos, tres meses en el caso de los actos del legislativo y veinte días en el de los actos de la autoridad militar, y especialmente en el primero, los que pueden obstaculizar la finalidad del amparo por ser plazos que permiten que la lesión puèda causar todos sus efectos y el derecho no pueda ser restituido. EI R. A. C. puede perder su finalidad por la cuantía de los plazos.

La subsidiariedad aparece, por el contrario, en los otros dos supuestos de actos recurribles: los del poder ejecutivo y los del judicial. Actos que, con seguridad, serán los más frecuentemente revisables ante el Tribunal Constitucional. Aquí no se sigue la regla general del Derecho alemán que implica, según VON MUNCH(31) «que los actos administrativos deben ser atacados en primera instancia ante el Tribunal Administrativo y que alli deben haber sido interpuestos todos los medios jurídicos admisibles (apelación, revisión), antes de que sea posible entablar el recurso de amparo. Cuando alguien se considere lesionado en sus derechos fundamentales o en los derechos equiparables a éstos por un fallo judicial, debe igualmente haber interpuesto todos los remedios jurídicos previstos para atacar ese fallo en el curso "normal" de las instituciones judiciales, antes de que pueda valerse del recurso de amparon.

En el caso de actos del poder ejecutivo será un procedimiento extraordinario, dentro del órgano judicial, la única vía previa al R. A. C. Sin embargo, es necesario detenerse en la observación de tal vía previa que, por el momento, no parece responder a la idea que-de ella se establece en la Constitución.

En principo, la via previa a la interposición del R. A. C. por actos lesivos de los gobiernos central y autónomos se halla enunciado en el artículo 53-2: “...ante los Tribunales ordinarios por un procedimiento basado en los principios de sumariedad y preferencian. No se trata, pues, de agotar la via ordinaria, como en el caso alemán, sino de un procedimiento especial dado dentro de la jurisdicción ordinaria, especialidad cuya razón de ser está en la intención de evitar el periculum in mora que tan dañino puede ser pa. ra la cualidad de los derechos que se protegen. El amparo ordinario del artículo 53-2 es tan especiấl que ALMAGRO NOSETE habla de un "recurso de amparo ante la jurisdicción ordinaria" y de un "recurso de amparo ante la jurisdicción constitucional»(32), equiparando ambas instituciones en su finalidad y abundando, por otra parte, en la idea que considera al ampara como un sistema autónomo de protección jurisdiccional, recogido en diversas instituciones.

Sin embargo, esto sería, en todo caso, lo constitucional ideal por cuanto el amparo ordinario no está debidamente desarrollado y se ve sus: 
tiuido por otro procedimiento que, por la complejidad de sus trámites y la dilación de los plazos, más que un filtro, supone un obstáculo al amparo. Por ahora, y en tanto no se cumplan debidamente las previsiones del artículo 52-2 de la Constitución, la vía previa a la impugnación mediante el R. A. C. de los actos lesivos del poder ejecutivo es la que se establece en la Disposición transitoria 2. ${ }^{2}-2$ L. O. T. C.: "En tanto no sean desarrolladas las previsiones del artículo cincuenta y tres, dos, de la Constitución para configurar el procemiento judicial de protección de los derechos y libertades fundamentales se entenderá que la vía judicial previa a la interposición del recurso de amparo será la contencioso-administrativa ordinaria o la configurada en la Sección segunda de la Ley sesenta y dos/mil novecientos setenta y ocho, de veintiseis de Diciembre, sobre protección jurisdiccional de los derechos fundamentles, a cuyos efectos el ámbito de la mişma se entiende extendido a todos. Ios derechos y libertades a que se refiere el expresado artículo cincuenta y tres, dos, de la Constitución".

La provisionalidad de esta disposición no se ve limitada por término alguno lo que puede suponer que, incluso formado definitivamente el Trjbunal Constitucional, tales procedimientos sustitutorios de los procedimientos establecidos por la Constitución-habeas corpus y el amparo ordinario-permanezcan sine die, sobre todo si se tiene en cuenta que no depende del citado Tribunal sino de las Cortes el desarrollo legal de dichos procedimientos. Hasta el momento, los sustitutorios recogidos en la Disposición transitoria 2 . $^{\mathrm{a}}$-2, L. O. T. C. y en la L. P. J. D. F. agravan los inconvenientes de la subsidiariedad; ello, al margen de la posible inconstitucionalidad de dicha ley, a la que ya se ha aludido(33).

La agravación de la subsidiariedad en el caso citado se ve, no obstante, atemperada por la propia L. O. T. C. que establece la cautela del "incidente de suspensión», del artículo 56, por el cual: "La Sala que conozca de un recurso de amparo suspenderá, de oficio o a instancia del recurrente, la ejecución del acto de los poderes públicos por razón del cual se reclama el amparo constitucional, cuando la ejecución hubiere de ocasionar un perjuicio que haría perder al amparo su finalidad". Esta disposición, encaminada, sin duda, a prevenir el periculum in mora, se ve compensada, de alguna manera, por una contracautela, de aplicación discrecional por el Tribunal Constitucional, que consiste en la prestación de una caución por posibles daños y perjuicios a terceros.

Respecto a la vía previa al R. A. C. en el caso de la impugnación de aetos provinientes del poder judicial, sí puede afirmarse que se está ante un caso claro de aplicación del principo de subsidiariedad en el sentido de que este se entiende por la doctrina y el Ordenamiento alemán. La L. O. T. C. es suficientemente explícita en el artículo 44: "Que se hayan agotado to. dos los recursos utilizables dentro de la vía judicials(34). 
La particular configuración del principio de subsidiariedad en el Derecho español ha de entenderse como el interés de la Constitución de evitar al máximo los inconvenientes del mismo que, en realidad y cuando se desarrollen definitivamente los procedimientos constitucionales, sólo juega su papel en el caso de actos lesivos del poder judicial. La vía previa al R. A. C. que se establece para el resto de los casos queda, en el momento actual del desarrollo legislativo, reforzada en detrimento de la idea de amparo, pero tanto ese desarrollo legislativo como la práctica jurisprudencial del Tribunal Constitucional pueden convertir a la subșidiariedad en un obstáculo mínimo en la protección de los derechos garantizados. Tan puede ser asi que si bien en el Ordenamiento alemán el principio de subsidiariedad es un requisito necesario del Verfassungsbeschwerde, en el español se trata de una excepción en consideración del poder judicial como "amparador natural" de los derechos fundamentales; $e$, incluso, puede significar que la vía previa no es una exigencia de la Constitución(35) y, por tanto, puede llegar a desaparecer en el desarrollo del sistema de garantias jurisdiccionales del Derecho español.

\section{CONCLUSION}

En todos los ordenamientos jurídicos de carácter democrático se dan históricamente sistemas de protección jurisdiccional de los derechos fundamentales; en el Derecho histórico español, destacan los llamados «procesos forales" del Derecho aragonés que muy bien pueden considerarse continuados por el sistema establecido en la Constitución de 1.978.

Por amparo se entiende, tanto en aquéllos como en el actual Derecho español, la actuación jurisdiccional tendente a evitar o interrumpir el acto de los poderes públicos lesivo de un derecho fundamental; actuación que, por la cualidad especial de los derechos que se protegen, es extraordinaria $y$ - requiere determinadas cautelás.

Ĺa Constitución de 1.978 establece un conjunto de instituciones llamadas a cumplir esa función en dos jurisdicciones: la ordinaria (habeas corpus, amparo ordinario del artículo 53-2 de la Constitución, y la constitucional). Dentro de la Constitución, al amparo se configura en el R. A. C. que presenta semejanzas notables con el Verfassungsbeschwerde alemán, sin que dejen de ser notables también las diferencias, entre las que destaca el desarrollo del principio de subsidiariedad, más mitigado en el R. A. C., y que consiste en el establecimiento de una vía judicial previa al recurso constitucional que cumple la función de filtro en los trámites de admisión de la demanda para evitar una superabundancia de asuntos que determinaría un funcionamiento irregular del Tribunal Constitucional. Sin embargo, la regulación de este principio se presenta delicada porque 
puede convertirse en un obstáculo a la finalidad del amparo que, no debe olvidarse, consiste primordialmente el evitar o interrumpir el acto lesivo.

En el estado actual de la legisláción española y en espera sobre todo de la definitiva formación del Tribunal Constitucional, de la reforma del poder judicial y del desarrollo orgánico de los artículos 17-4 y 53-2 de la Constitución, no puede afirmarse que exista un sistema de garantías jurisdiccionales propio de un Estado democrático, en el sentido que aquí se ha querido dar al amparo. Solo el criterio de los jueces ordinarios, vagamente determinado por el artículo 9 de la Constitución, puede soslayar esta deficiencia que parece circunstancial. Ello sin entrar en consideraciones sociológicas sobre el poder judicial en España que desbordan los límites del presente trabajo pero que, posiblemente, son las más determinantes en el funcionamiento de un sistema jurisdiccional de protección de los derechos garantizados por la Constitución.

\section{NOTAS:}

(1) El proyecto de ley del Tribunal de Garantías Constitucionales aludia a la falta de tradición nacional que pudiera orientar el rumbo de la institución. Apéndice número 1 del Diario de Sesiones de 23 de Diciembre de 1.932, citado por José Luis GARCIA RUIZ, "El recurso de amparo en el Serecho españoln, Ed. Nacional, Madrid, 1:980, p. 45.

(2) Una de las formas de la Manifestación de personas a posse privatorum o Manifestación de aquellas personas que se ahllan retenidas por particulares hace pensar en un supuesto de hecho que no se halla regulado en los sistemas actuales y que puede ser una violación de la seguridad y libertad personales por el acto de una "autoridad", si bien no se trata de una autoridad pública: La retención de menores por parte de los padres, tutores u otras personas encargadas de su custodia. El menor goza naturalmente de los derechos fundamentales que la Constitución reconoce y puede verse sometido a situaciones de tratos infamantes; retenciones temporales, torturas y demás vejaciones por parte de quien ostenta su tutela jurídica que, si bien no se trata de un poder público en sentido estricto, sí cumple respecto del menor un papel similar de autoridad.

(3) Sobre Derecho historico aragonés: Victor FAIREN GUILLEN, «Los procesos medievales aragoneses y los derechos del hombren, Anuario de Derecho aragonés, Zaragoza, 1.968-69; "Antecedentes aragoneses de los juicios de amparo", México, 1.971; "El proceso aragonés de Manifestación y el británico de habeas corpus", en Temas del Ordenamiento procesal, Tomo I, Madrid, 1.969. También Francisco SAENZ DE TEJADA Y DE OLOZAGA, "El Derecho de Manifestación aragonés y el Habeas corpus inglés", Madrid.

(4) Vid. Héctor FIX-ZAMUDIO, "El derecho de amparo en México y España», Revista de Estudios Políticos (REP), número 7, Madrid, 1.979, p. 228; en donde se recoge una interesante bibliografía sobre la influencia del Derecho español en el juicio de amparo mexicano.

(5) La Giurisdizione Costituzionale delle libertá (Grundrechtsgerichtsbarkeit), expresión debida a Mauro CAPPLETI, recogida en México por FIX-ZAMUDIO y en España por José Luis 
CASCAJO como uJurisdicción constitucional de la libertad", es considerada por el autor italiano como la expresión piu raffinata de la renovación jurídica de la postguerra y una de las grandes directrices de la evolución del Derecho contemporáneo. Para un conocimiento amplio y profundo de la materia, en lo sustantivo y en lo biográfico, es imprescindible la consulta del excelente y temprano artículo de José Luis CASCAJO, "La Jurisdicción constitucional de la libertad», $R$. $E$. $P .$, número 199, Madrid, 1.975, pp. 149-98.

(6) Citado por José Luis CASCAJO, ob. cit., p. 164.

(7) Jòsé ALMAGRO NOSETE, «Justicia Constitucional", Madrid, 1.980, P. 199.

(8) Artículo 10 de la Constítución española de 1.978: "La dignidad de la persona, los derechos inviolables que le son inherentes, el libre desarrollo de la personalidad, ehrespeto a la ley y a los derechos de los demás son fundamentales del orden politico y de la paz social".

(9) .José Luis GARCIA RUIZ, ob. cit., p. 30

(10) F. C. E. México, 2. ${ }^{2}$ ed., 1.963, p. 111.

(11) "El organismo judicią en México y España», R. E. P., número 10, 1.979, p. 26.

(12) José AMAGRO NOSETE, ob. cit., p. 198.

(13) Idem., p. 207.

(14) La adhesión española (24-11-77) a la Convención europea para la protección de los Derechos Humanos (roma, 4-11-50) no supone, por el momento, el enriquecimiento del sistema español de protección de los derechos al no haberse ratíficado, por el correspondiente protocolo, el artículo 25 de la Convención por el que ésta admite las demandas individuales.

(15) Sin embargo, cabe que del amparo se derive una cuestión de inconstitucionalidad porque el acto impugnado se haya realizado en atención a una ley inconstitucional; en tal supuesto, la cuestión se eleva al Pleno por si procede declarar la inconstitucionalidad de dicha ley (artículo 55 L. O. T. C.7.

(16) Según FIX-ZAMUDIO, el amparo mexicano encierra las siguientes instituciones: Habeas corpus, control de la constitucionalidad de las leyes, una especie de casación contencioso-administrativo y un procedimiento de otorgamiento de privilegios procesales (igualdad de compensación) a los campesinos afectados por la Reforma agraria. "El Derecho de amaparo en México y Españan, R. E. P., número 7, Madrid, 1.979, pp. 236-39.

(17) The American Political Dictionary, 3. ${ }^{a}$ ed., The Dryden Press. Inc. Hinsdale, Illinois, $p$. 12.

(18) Las libertades que, según la doctrina francesa (Jacques ROBERT, "Libertés publiques", París, 1.971; Georges BURDEAU, "Les libertés publiques", Paris, 1.972; Jean ROCHE, Libertés publiques", París, 1.971), condicionan el ejercicio de las demás, son: la igualdad, la seguridad y el derecho de propiedad privada, entendido por seguridad la libertad física (liberté d'aller et vénir) y el derecho a la intimidad. En la actual Constitución española parece ser que se prescinde de establecer categorías dentro de las libertades fundamentales, y todas las recogidas en los artículos 14-30 tienen esa misma consideración, de lo que da idea los artículos 10 y 53 de la Constitución. Por otra parte, el derecho de propiedad privada no se incluye en el catálogo de derechos generalizados, 10 que hace suponer que no tiene la consideración de derecho fundamental, ello acentúa el carácter más progresivo de la Constitución de 1.978 respecto de otros ordenamientos contemporáneos.

(19) Hay que hacer notar que no existen modelos de sistemas.de protección sino tipos específicos que se influencian reciprocamente $y$, por tanto, no resulta del todo exacto habiar de un sistema anglosajón y otro continental sobre los que se basen todos los existentes, sino que cada país ha elaborado su sistema partiendo de elementos propios tradicionales que se conjugan con otros resultados del constitucionalismo contemporáneo y la racionalización del poder que él mismo impliça, el cual "pone i fondamenti sostantivi e procedulari di tuțto il sistema del 
diritto politico", A. LA PERGOLA, "Le garanzie giurisdizionali della Costituzionen, en La Costituzione Spagnola, Bologna, 1.978, p. 33-4.

(20) Parece haber una contradición entre el artículo 81 de la Constitución, que al definir qué son leyes orgánicas señala en primer lugar aquéllas urelativas al desarrollo de los derechos fundamentales y de las libertades públicas", y el artículo 53-1 cuando establece que "sólo por ley-sin especificar orgánica_-podrá regulaese el ejercicio de tales derechos". De la solución a esta contradicción dependerá en gran parte la constitucionalidad de la Ley de Protección Jurisdiccional de los Derechos Fundamentales de 26 de Diciembre de 1.978 (L. P. J. D. F.).

(21) Ob. cit. p. 191.

(22) Ob. cit. p. 47.

(23) FIX-ZAMUDIO, ob. cit. p. 230-231.

(24) Jacques ROBERT, ob. cit., p. 123. También, Francisco RUBIO LLORENTE, "La Defen\$a de la igualdad política en la reciente jurisprudencia de la Corte Suprema nortamericanan, Uni. versidad Central de Venezuela, Facultad de Derecho de Caracas, 1.966.

(25) Ob. cit., p. 223.

(26) José Luis CASCAJO, ob. cit., p. 172, J. ALMAGRO NOSETE, ob. cit., p. 225.

(27) Igo VON MÜNCH, «El recurso de amparo constitucional", R. E. P., número 7, Madrid, 1.980, p. 277.

(28) José Luis CASCAJO, ob. cit., p. 178-79.

(29) Ob. cit., p. 262.

(30) Ingo VON MÜNCH, ob. cit., p. 283.

(31) Idem., p. 277.

(32) ALMAGRO NOSETE, ob. cit., p. 225.

(33) Vide supra nota 20. La posible inconstitucionalidad de la L. P. J. D. F. puede ser un ejemplo de la llamada inconstitucionalidad sobrevenida, (Vid. ALMAGRO NOSETE, ob. cit., p. 426); con la curiosa particularidad de que se trata de una ley del 26 de Diciembre, anterior a la Constitución, que se publica en el B. O. E. EL 3 de Enero de 1.979 , o sea, después de promulgada la Constitución.

(34) ALMAGRO NOSETE entiende que la "via judicial" a la que se refiere el artículo 44-a) . de la L. O. T. C. es la misma que establece la Disposición transitoria $2 .^{2} \cdot 2$ (ob. cit., p. 226), es decir, el recurso contencioso-administrativo y los procedimientos establecidos en la L. P. J. D. F. Sin embargo, quizá quepa otra interpretación del precepto si se piensa en la especial consideración que el Tribunal Constitucional mantiene respecto del organo judicial al que parece conceder que sea dentro de su propia jurisdiccion, y por los procedimientos ordinarios, donde se intente subsanar la lesión; ello sólo se puede afirmar pensando en un órgano judicial independiente, con un elevado sentido democrático y comprometido en la salvaguarda de los derechos fundamentales, como le atribuye la Constitución en los artículos 9-1, 24 y 53-3.

(35) ALMAGRO NOSETE, ob. cit., p. 226. 